\title{
TRATEGI MENINGKATKAN KINERJA SUMBER DAYA MANUSIA MELALUI BUDAYA ORGANISASI
}

\author{
IAN PERMANA WAHYU
}

Dosen Pendidikan Ekonomi, Universitas Pamulang

ian.permana@gmail.com

\begin{abstract}
ABSTRAK
Banyaknya lembaga-lembaga pendidikan yang berbasis Islami. Untuk menyikapi persaingan tersebut maka dibutuhkan pembenahan dari dalam yayasan. Kondisi ini diharuskan yayasan harus menciptakan strategi agar dapat bersaing dan bertahan untuk menjalankan perekonomian yayasan. Penelitian ini bermaksud untuk merumuskan strategi meningkatkan sumber daya manusia dilingkunan Yayasan Masjid Al Ikhlas (YMAI). Penelitian dilakukan dengan menggunakan metode observasi, wawancara dan fokus group diskusi. Analisis data menggunakan metode triangulasi, analisis SWOT dan FGD. Hasil penelitian menunjukan bahwa: (1) Budaya Organisasi yang erat yang saling mempengaruhi antara lingkungan kerja perusahaan dapat meningkatkan kinerja atau prestasi kerja. (2) Mendayagunakan secara optimal keuntungan kekuatan dengan cara melaksanakan tindakan kekuatan yayasan. (3) Komponen kinerja yang dapat diukur yang meliputi hasil kerja. Dengan ini harus adanya standar kerja yang menjadi acuan kerja sehingga hasil penilaian kinerja akan memberikan hasil yang objektif.
\end{abstract}

Kata Kunci: Budaya Organisasi, Strategi, Analisis SWOT, Kinerja 


\section{PENDAHULUAN}

Pertumbuhan pesat di
bidang jasa penyelengara
pendidikan swasta telah mendorong
lembaga-lembaga pendidikan
meningkatkan kinerja sumber daya
manusia mereka dalam
berkompetisi untuk menjadi
lembaga pendidikan yang dipilih
bagi mereka yang membutuhkan,
sehingga di saat bersamaan seluruh
penyedia jasa pendidikan belomba-
lomba menawarkan kualitas dan
jasa layanan yang lebih baik. Untuk
dapat menciptakan suatu
keunggulan dalam berkompetisi
maka perlu direncanakan strategi
peningkatan kinerja sumber daya
manusia yang akan digunakan,
sebagaimana diketahui bahwa
strategi adalah alat yang sangat
penting untuk mencapai keunggulan
bersaing (Porter, 1985).

Menurut Stoner, Freeman, dan Gilbert. Jr ( 2001 ), konsep strategi dapet didefinisikan berdasarkan 2 prespektif yang berbeda yaitu : (1) dari perspektif apa suatu organisasi ingin dilakukan ( intends to do ), dan (2) dari perspektif apa yang organisasi akhirnya lakukan ( eventually does ). Berdasarkan perspektif yang pertama, strategi dapat didefinisikan sebagai program untuk menentukan dan mencapai tujuan organisasi dan implementasi misinya. Artinya, bahwa para manajer memainkan peranan penting yang aktif, sadar dan rasional dalam merumuskan strategi organisasi. Sedangkan berdasarkan perspektif kedua, strategi didefinisikan sebagai pola tanggapan atau respon organisasi terhadap lingkungannya sepanjang waktu. Pada definisi ini, setiap organisasi pasti memiliki strategi, meskipun strategi tersebut tidak pernah dirumuskan secara eksplisit. Pandangan ini diterapkan bagi para manajer yang bersifat reaktif, yaitu hanya menanggapi dan menyesuaikan diri terhadap lingkungan secara pasif manakala dibutuhkan. Pernyataan strategi secara eksplisit merupakan kunci keberhasilan dalam menghadapi perubahan lingkungan bisnis. Strategi memberikan kesatuan arah bagi semua anggota organisasi. Bila konsep strategi tidak jelas, maka keputusan yang diambil akan bersifat subyektif atau berdasarkan intuisi belaka dan mengabaikan keputusan yang lain. Konsep strategi setiap organisasi dalam mencapai tujuannya perlu merumuskan dan merencanakan langkah-langkah apa yang harus dilakukan secara terukur, terarah dan jelas dengan memanfaatkan sumber daya yang dimilikinya. Perencanaan yang dituangkan dalam langkah-langkah itu disebut dengan strategi.

Mulyadi (2007:337) yang menyatakan bahwa: "kinerja adalah keberhasilan personel, tim, atau unit organisasi dalam mewujudkan sasaran strategik yang telah ditetapkan sebelumnya dengan 
perilaku yang diharapkan”. Pendapat yang lain mengenai definisi kinerja juga diungkapkan oleh Indra Bastian (2006: 274) yang menyatakan bahwa: Kinerja adalah gambaran pencapaian pelaksanaan suatu kegiatan/program/kebijaksanaan

dalam mewujudkan sasaran, tujuan, misi, dan visi organisasi. Daftar apa yang ingin dicapai tertuang dalam perumusan penskemaan strategis (strategic planning) suatu organisasi. Secara umum, kinerja merupakan prestasi yang dicapai oleh organisasi dalam periode tertentu. Pendapat yang senada juga dijelaskan oleh Veithzal Rivai (2008:14) yang mengungkapkan bahwa. Kinerja adalah hasil atau tingkat keberhasilan seseorang secara keseluruhan selama periode tertentu di dalam melaksanakan tugas dibandingkan dengan berbagai kemungkinan, seperti standar hasil kerja, target atau sasaran 9 atau kriteria yang telah ditentukan terlebih dahulu dan telah disepakati bersama. Berdasarkan definisi-definisi di atas, disimpulkan dua hal sebagai berikut. Pertama, kinerja dapat didefinisikan sebagai hasil akhir dari keseluruhan kegiatan yang dilakukan oleh perusahaan yang disesuaikan dengan kriteria-kriteria yang telah ditetapkan. Kedua, kinerja juga mencerminkan prestasi yang dicapai oleh suatu organisasi. Konsep kinerja kemampuan setiap organisasi untuk dapat mencapai kinerja organisasi yang diharapkan berkaitan erat dengan kinerja dari sumber daya manusia yang dimilikinya, untuk itu setiap perusahaan akan berusaha untuk meningkatkan kinerja sumber daya manusianya dalam mencapai tujuan organisasi yang telah ditetapkan.

Edgar H. Schein (2010), Budaya organisasi adalah pola asumsi dasar yang ditemukan atau dikembangkan oleh suatu kelompok orang selagi mereka belajar untuk menyelesaikan persoalan, menyesuaikan diri dengan lingkungan eksternal dan berintegrasi dengan lingkungan internal.Setiap organisasi memiliki budaya organisasi yang mempengaruhi semua aspek secara individu dan kelompok, Peter F. Druicker dalam buku Robert G. Owen, Organizational Behavior in Education. Budaya organisasi adalah pokok penyelesaian masalah-masalah eksternal dan internal yang pelaksanaannya dilakukan secara konsisten oleh suatu kelompok yang kemudian mewariskan kepada anggota-anggota baru sebagai cara yang tepat untuk memahami, memikirkan dan merasakan terhadap masalah-masalahterkait. Kemudian Phithi Sithi Amnuai dalam tulisannya HowtoBuild a Corporation Culture dalam majalah Asian Manajer (September 1989), Budaya Organisasi adalah seperangkat asumsi dasar keyakinan yang dianut oleh anggota-anggota organisasi, kemudian dikembangkan dan diwariskan guna mengatasu masalah- 
masalah adaptasi eksternal dan masalah integrasi internal.Melihat beberapa pendapat para ahli tentang budaya organisasi, dapat ditarik benang merah bahwa budaya organisasi merupakan suatu nilainilai yang dipercayai sehingga menjadi karakteristik yang diberikan anggota kepada suatu organisasi.

Fakta strategi pada Yayasan Masjid Al Ikhlas adalah bahwa belum adanya suatu strategi yang dirumuskan untuk meningkatkan kinerja dari sumber daya manusia pada seluruh lini organisasi. Strategi masih menganut pola piker apa yang pada akhirnya dilakukan organisasi.

Kondisi yang ada di objek penelitian berdasarkan hasil evaluasi internal yang dilakukan kinerja sumber daya manusia di Yayasan Masjid Al Ikhlas di seluruh bagian belum mencapai tingkat kinerja yang mendukung kepada pencapaian tujuan organisasi. Hal tersebut terjadi pada seluruh unit yang ada mulai dari tenaga kerja pengajar, tenaga kerja administrasi dan tenaga kerja pendukung.

Fakta Budaya Organisasi. Berdasarkan hasil evaluasi internal, budaya organisasi di Yayasan Masjid Al Ikhlas sebagai lembaga penyelenggara pendidikan di nilai masih lemah, nilai-nilai budaya organisasi belum terangkum sebagai satu kesatuan budaya yang disepakati oleh anggota organisasi. Demikian pula dengan artifak atau bentuk kasat mata dari nilai-nilai masih berupa bagian-bagian terpisah. Hal ini dinilai menjadi faktor yang sangat penting mengingat bahwa sebagai penyelanggara pendidikan tentu harus dapat mencerminkan nilai-nilai budaya yang akan menjadi acuan dari kualitas pendidikan yang diberikan.

Fenomena kinerja pegawaidi Yayasan Masjid Al Ikhlas yang dilihat dari sudut pandang kedisiplinan, peneliti mendapatkan data absensi dan data lainya dari bagian kepegawaian sebagai berikut

Tabel 1.1

\begin{tabular}{|c|c|c|c|c|c|}
\hline \multirow{2}{*}{ No } & \multirow{2}{*}{ Bulan } & \multirow{2}{*}{ Jumlah } & \multicolumn{3}{|c|}{ PerincianTidakMasuk } \\
\cline { 4 - 6 } & & & TanpaKeterangan & Sakit & Ijin \\
\hline 1 & Januari & 9 & 0 & 6 & 3 \\
\hline 2 & Februari & 8 & 0 & 3 & 5 \\
\hline 3 & Maret & 12 & 0 & 9 & 3 \\
\hline 4 & April & 13 & 0 & 7 & 6 \\
\hline 5 & Mei & 16 & 0 & 4 & 8 \\
\hline 6 & Juni & 8 & 0 & 11 & 4 \\
\hline 7 & Juli & 19 & 0 & 5 & 2 \\
\hline 8 & Agustus & 7 & 0 & 9 & 5 \\
\hline 9 & September & 14 & 0 & & 8 \\
\hline
\end{tabular}

Absensi karyawan Yayasan Masjid Al Ikhlas

Sumber :Bagian Kepegawaian (2016) 
Jika kita memperhatikan tabel di atas, ketidakhadiran dari 168 jumlah pegawai masih terdapat ijin dan sakit memang tergolong sedikit, sekilas tampaknya bukan masalah besar. Tetapi sesungguhnya dalam berorganisasi hal itu dapat membawa pengaruh buruk dan akan memperhambat perkembangan Yayasan Masjid Al Ikhlas.

\section{HASIL DAN PEMBAHASAN}

\section{Matrix SWOT}

\section{Analisis}

SWOT

menggunakan teknik atau alat yang disebut Matriks

SWOT untuk mengaudit atau menilai sebuah organisasi beserta lingkungannya. Dalam kerangka analitis perumusan strategi, Analisis SWOT merupakan langkah pertama dalam Tahap Pencocokan.

Gambaran yang skematis dari Matriks SWOT ditampilkan pada figur di bawah ini. Perhatikan bahwa sebuah Matriks SWOT terdiri atas sembilan sel. Sebagaimana ditunjukkan, ada empat sel faktor utama, empat sel strategi, dan satu sel yang dibiarkan kosong (sel kiri atas).

Berdasarkan dari proses wawancara yang sudah dilakukan pada tahap sebelumya. Peneliti merangkum untuk disajikan dalam table matrix SWOT, dimaksud untuk mempermudah dalam proses penyajian.

\section{Matrix SWOT}

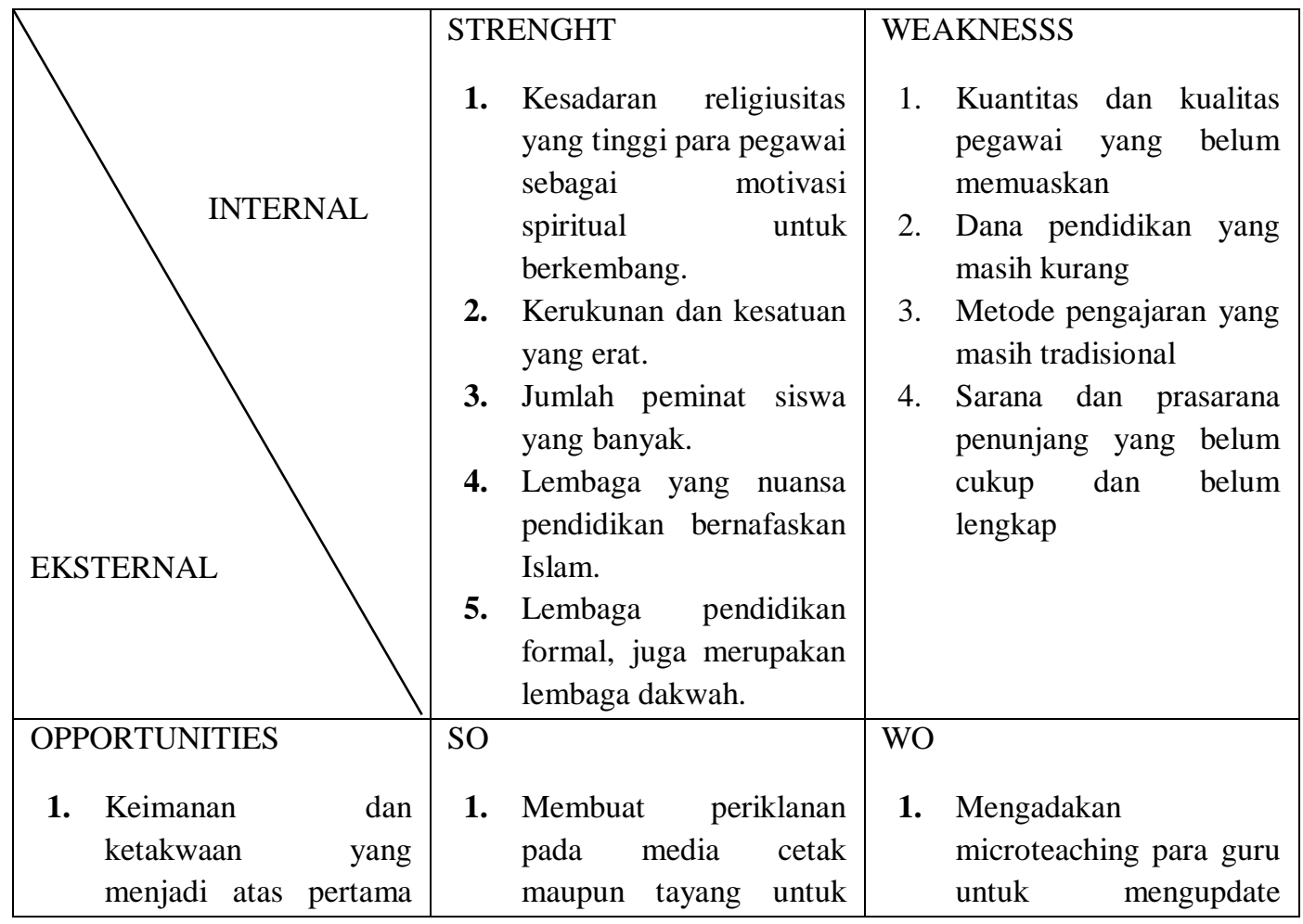




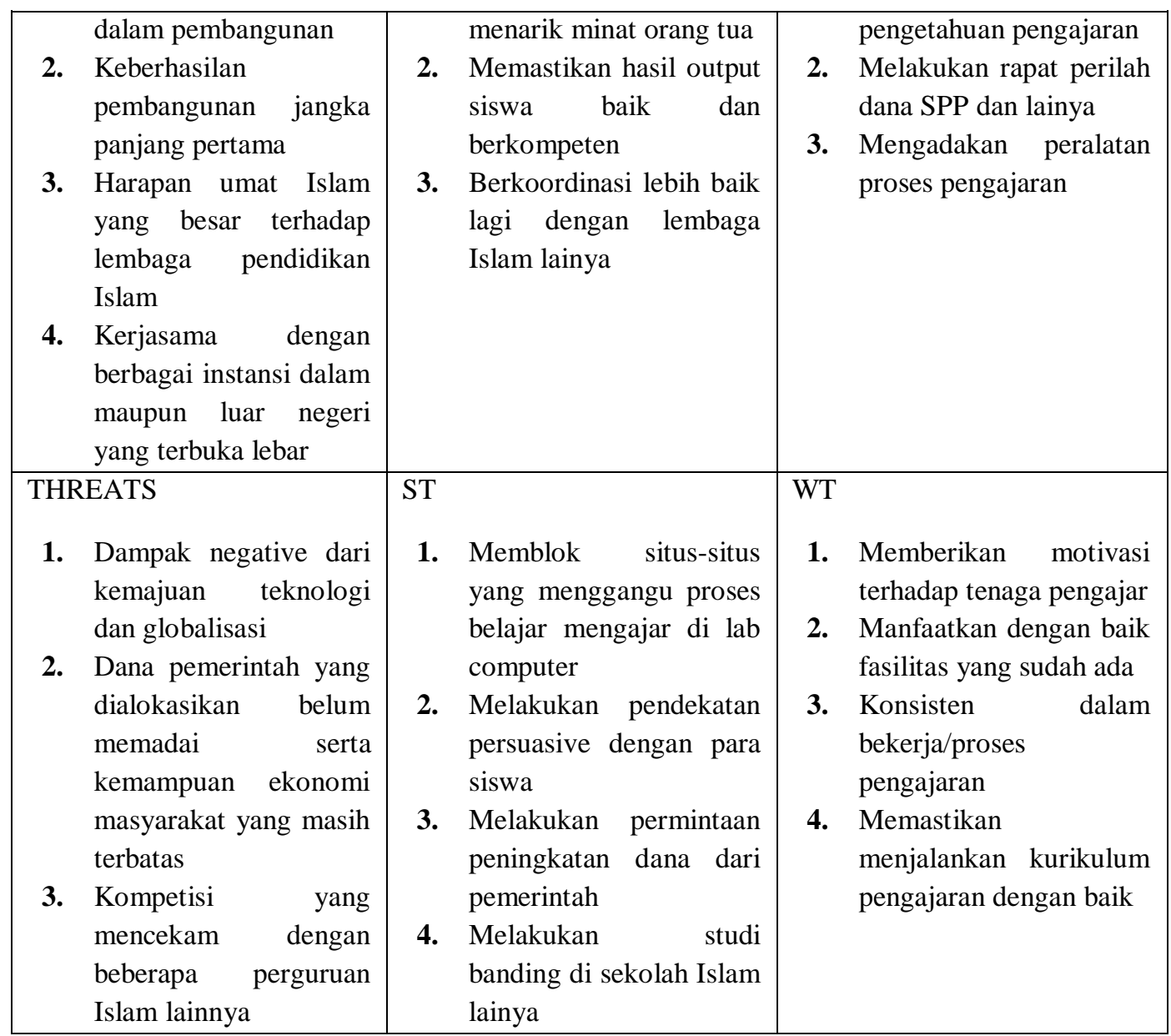

Sumber : (FGD 14 November 2016)

Tabel 1

Faktor Strategi Internal

\begin{tabular}{|c|c|c|c|c|}
\hline Faktor-faktor strategi internal & Bobot & Rating & $\begin{array}{l}\text { Bobot } \\
\text { X } \\
\text { Rating }\end{array}$ & Komentar \\
\hline KEKUATAN: & & & & \\
\hline $\begin{array}{l}\text { 1. Kesadaran religiusitas } \\
\text { yang tinggi para pegawai } \\
\text { sebagai motivasi spiritual } \\
\text { untuk berkembang. }\end{array}$ & 0.20 & 4 & 0.80 & $\begin{array}{l}\text { Lebih ditingkatkan } \\
\text { pemberian motivasi }\end{array}$ \\
\hline $\begin{array}{l}\text { 2. Kerukunan dan kesatuan } \\
\text { yang erat. }\end{array}$ & 0.15 & 4 & 0.60 & Harus dipertahankan \\
\hline $\begin{array}{l}\text { 3. Jumlah peminat siswa } \\
\text { yang banyak. }\end{array}$ & 0.15 & 4 & 0.60 & $\begin{array}{l}\text { Tetap konsisten dalam } \\
\text { penerimaan siswa }\end{array}$ \\
\hline $\begin{array}{l}\text { 4. Lembaga yang nuansa } \\
\text { pendidikan bernafaskan } \\
\text { Islam. }\end{array}$ & 0.20 & 3 & 0.60 & $\begin{array}{l}\text { Perlu hati-hati banyak } \\
\text { tantangan baru }\end{array}$ \\
\hline 5. Lembaga pendidikan & 0.10 & 3 & 0.30 & diperhatikan \\
\hline
\end{tabular}




\begin{tabular}{|c|c|c|l|l|}
\hline $\begin{array}{c}\text { formal, juga merupakan } \\
\text { lembaga dakwah. }\end{array}$ & & & \\
\hline $\begin{array}{c}\text { KELEMAHAN: } \\
\text { 1. } \begin{array}{l}\text { Kuantitas dan kualitas } \\
\text { pegawai yang belum } \\
\text { memuaskan }\end{array}\end{array}$ & 0.02 & 2 & 0.04 & $\begin{array}{l}\text { Ditingkatkan mengadakan } \\
\text { pelatihan }\end{array}$ \\
2. $\quad \begin{array}{l}\text { Dana pendidikan yang } \\
\text { masih kurang }\end{array}$ & 0.05 & 3 & 0.15 & Perhatikan dan diajukan \\
3. $\begin{array}{l}\text { Metode pengajaran yang } \\
\text { masih tradisional } \\
\text { Sarana dan prasarana }\end{array}$ & 0.05 & 3 & 0.15 & Diadakan microteaching \\
$\quad \begin{array}{l}\text { penunjang yang belum } \\
\text { cukup dan belum lengkap }\end{array}$ & 1.00 & 2 & 0.16 & Segera dilengkapi \\
\hline TOTAL & 3.40 & \\
\hline
\end{tabular}

Sumber : (FGD 14 November 2016)

Keterangan :

SB : Sangat Baik

DRR : Di Atas Rata-Rata

RR : Rata-Rata

DIRR : Di Bawah Rata-Rata

Komentar:

Hasil dari factor strategi internal pada Yayasan Islam Al Ihklas yaitu kondisi internal tegolong Diatas Rata-rata cendrung Sangat baik, sehingga seluruh komponen yang ada pada yayasan tetap konsisten dalam menjalankan tugas dan tanggung jawabnya.

Tabel 2

Faktor Strategi Internal

\begin{tabular}{|c|c|c|c|c|}
\hline Faktor-faktor strategi eksternal & Bobot & Rating & $\begin{array}{c}\text { Bobot } \\
\text { X } \\
\text { Rating }\end{array}$ & Komentar \\
\hline PELUANG: & & & & \\
\hline $\begin{array}{l}\text { 1. Keimanan dan ketakwaan } \\
\text { yang menjadi atas pertama } \\
\text { dalam pembangunan }\end{array}$ & 0.20 & 4 & 0.8 & Peluang yayasan \\
\hline $\begin{array}{l}\text { 2. Keberhasilan pembangunan } \\
\text { jangka panjang pertama }\end{array}$ & 0.20 & 3 & 0.6 & 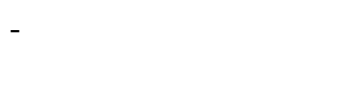 \\
\hline $\begin{array}{l}\text { 3. Harapan umat Islam yang } \\
\text { besar terhadap lembaga } \\
\text { pendidikan Islam }\end{array}$ & 0.15 & 4 & 0.6 & $\begin{array}{l}\text { diperhatikan dan hati- } \\
\text { hati }\end{array}$ \\
\hline $\begin{array}{l}\text { 4. Kerjasama dengan berbagai } \\
\text { instansi dalam maupun luar } \\
\text { negeri yang terbuka lebar }\end{array}$ & 0.00 & 4 & 0.2 & perhatikan dan jalankan \\
\hline
\end{tabular}




\begin{tabular}{|l|l|l|l|l|}
\hline $\begin{array}{l}\text { ANCAMAN: } \\
\text { 1. } \begin{array}{l}\text { Dampak negative dari } \\
\text { kemajuan teknologi dan } \\
\text { globalisasi }\end{array}\end{array}$ & 0.10 & 3 & 0.3 & Monitoring siswa \\
2. $\begin{array}{l}\text { Dana pemerintah yang } \\
\text { dialokasikan belum memadai } \\
\text { serta kemampuan ekonomi } \\
\text { masyarakat yang masih } \\
\text { terbatas }\end{array}$ & 0.05 & 2 & 0.1 & $\begin{array}{l}\text { Sesuaikan anggaran dan } \\
\text { pembiayaan }\end{array}$ \\
3ompetisi yang mencekam \\
$\begin{array}{l}\text { dengan beberapa perguruan } \\
\text { Islam lainnya }\end{array}$
\end{tabular}

Sumber : (FGD 14 November 2016)

\begin{tabular}{|c|l|l|l|} 
4 SB3.60 & 3 DRR & $2 \mathrm{RR}$ & $1 \mathrm{DIRR}$ \\
\hline$\downarrow$ & & &
\end{tabular}

Keterangan :

SB : Sangat Baik

DRR : Di Atas Rata-Rata

RR : Rata-Rata

DIRR : Di Bawah Rata-Rata

Komentar:

Hasil dari factor strategi eksternal pada Yayasan Islam Al Ihklas yaitu kondisi internal tegolong Sangat baik, manajemen harus lebih memperhatikan peluangpeluang yang ada manfatkan semua peluang dengan kekuatan internal, tetap konsisten dalam menghadapi ancaman eksternal.

\section{PEMBAHASAN}

\section{Budaya Organisasi di Yayasan Masjid Al Ikhlas (YMAI)}

Hubungan yang erat, yang saling mempengaruhi antara lingkungan kerja perusahaan. Maka pegawai akan termotivasi untuk berkerja dengan baik dengan memberikan kinerja atau prestasi kerja yang lebih, karena mereka menemukan hubungan yang baik antara atasan dan bawahan, mitra yang baik dengan sesama rekan kerja, peraturan dan kebijakan perusahaan yang netral dan adil serta kompensasi yang diterima atas prestasi kerja yang telah dicapainya.

\section{Strategi Yayasan Masjid Al} Ikhlas (YMAI)
a. Kekuatan menghadapi Peluang 
1) Membuat periklanan pada media cetak maupun tayang untuk menarik minat masyarakat

2) Memastikan hasil output siswa baik dan berkompeten

3) Berkoordinasi lebih baik lagi dengan lembaga Islam lainya

b. Pemanfaatan Peluang dalam meminimalkan Kelemahan

1) Mengadakan microteaching para guru untuk mengupdate pengetahuan pengajaran

2) Melakukan rapat perilah dana SPP dan lainya

3) Mengadakan peralatan proses pengajaran

c. Menggunakan Kekuatan dalam mengatasi Ancaman

1) Memblok situs-situs yang menggangu proses belajar mengajar di lab computer

2) Melakukan pendekatan persuasive dengan para siswa

3) Melakukan permintaan peningkatan dana dari pemerintah

4) Melakukan studi banding di sekolah Islam lainya

d. Bertahaan dengan cara mengurangi Kelemahan serta menghindari Ancaman
1) Memberikan motivasi terhadap tenaga pengajar

2) Manfaatkan dengan baik fasilitas yang sudah ada

3) Konsisten dalam bekerja/proses pengajaran

4) Memastikan menjalankan kurikulum pengajaran dengan baik

e. Komentar Internal Faktor Strategi (IFAS)

Hasil dari factor strategi internal pada Yayasan Islam Al Ihklas yaitu kondisi internal tegolong Diatas Rata-rata cendrung Sangat baik, sehingga seluruh komponen yang ada pada yayasan tetap konsisten dalam menjalankan tugas dan tanggung jawabnya.

f. Komentar Eksternal Faktor Strategi (EFAS)

Hasil dari factor strategi eksternal pada Yayasan Islam Al Ihklas yaitu kondisi internal tegolong Sangat baik, manajemen harus lebih memperhatikan peluangpeluang yang ada manfatkan semua peluang dengan kekuatan internal, tetap konsisten dalam menghadapi ancaman eksternal. 
g. Komentar Matrix Space

Mendayagunakan

secara optimal keuntungan

kekuatan keuangan dengan

cara melaksanakan tindakan

tindakan kekuatan yayasan yaitu, nama besar yayasan, Sumber Daya Manusia yang berkualitas, kondisi keuangan baik dan pemanfaatan potensi Sumber Daya Manusia.

3. Kinerja di Yayasan Masjid Al Ikhlas (YMAI)

Hasil diskusi mencerminkan bahwa kinerja yang ada di lingkungan Yayasan Masjid Al Ikhlas yaitu cukup baik. Hal ini didasarkan oleh pernyataan petinggi-petinggi yayasan, perlu kiranya manajemen yayasan melakukan evaluasi kinerja untuk meningkatkan kinerja pegawai demi tercapainya visi dan misi Yayasan Masjid Al Ikhlas (YMAI).

Dapat disimpulkan bahwa diperlukan standar kinerja yang jelas dalam memberikan penilaian kinerja. Standar penilaian kinerja tersebut memiliki komponen kinerja yang dapat diukur yang meliputi hasil kerja (tingkat pencapaian kerja), pegawai yang melaksanakan kerja (individu), bukti kerja (konkret maupun non konkret), dan adanya standar kerja yang menjadi acuan kerja sehingga hasil penilaian kinerja akan memberikan hasil yang obyektif Hal ini menunjukkan bahwa kualitas kerja di Yayasan Masjid Al Ikhlas (YMAI) sudah tergolong baik. Hal ini juga didasarkan pada hasil pengamatan oleh peneliti, bahwa kualitas kerja di Yayasan Masjid Al Ikhlas (YMAI) sudah terlihat baik, walaupun masih perlu peningkatan.

\section{KESIMPULAN}

Berdasarkan hasil penelitian di Yayasan Masjid Al Ikhlas (YMAI), maka dapat diambil kesimpulan sebagai berikut.

1. Budaya Organisasi, hubungan yang erat yang saling mempengaruhi antara lingkungan kerja perusahaan. Maka pegawai akan termotivasi untuk berkerja dengan baik dengan memberikan kinerja atau prestasikerja yang lebih, karena mereka menemukan hubungan yang baik antara atasan dan bawahan, mitra yang baik dengan sesama rekan kerja, peraturan dan kebijakan perusahaan yang netral dan adil serta kompensasi yang diterima atasprestasikerja yang telahdicapainya.

2. Strategi Yayasan
a. KomentarInternal Faktor Strategi (IFAS) 
Hasildari factor strategi internal padaYayasan Islam Al Ihklas yaitu kondisi internal tegolong Diatas Rata-rata cendrung Sangat baik, sehingga seluruh komponen yang ada pada yayasan tetap konsisten dalam menjalankan tugas dan tanggungjawabnya.

b. KomentarEksternal Faktor Strategi (EFAS)

Hasildari factor strategi eksternal pada Yayasan Islam $\mathrm{Al}$ Ihklas yaitu kondisi internal tegolong Sangat baik, manajemen harus lebih memperhatikan peluang-peluang yang ada manfatkan semua peluang dengan kekuatan internal, tetap konsisten dalam menghadapi ancaman eksternal.

c. Komentar Matrix Space

Mendayagunakan secara optimal keuntungan kekuatan keuangan dengan cara melaksanakan tindakan-tindakan kekuatan yayasan yaitu, nama besar yayasan, Sumber Daya Manusia yang berkualitas, kondisi keuangan baik dan pemanfaatan potensi Sumber Daya Manusia.

3. Kinerja

Standar kinerja yang jelas dalam memberikan penilaian kinerja. Standar penilaian kinerja tersebut memiliki komponen kinerja yang dapat diukur yang meliputi hasil kerja (tingkat pencapaian kerja), pegawai yang melaksanakan kerja (individu), bukti kerja (konkret maupun non konkret), dan adanya standar kerja yang menjadi acuan kerja sehingga hasil penilaian kinerja akan memberikan hasil yang obyektif

\section{REFERENSI}

Alwi, (2001). Manajemen Sumber Daya Manusia Keunggulan, BPFEUGM, Yogyakara.

Anwar Prabu Mangkunegara, (2006). Evaluasi Kinerja SDM, Refika Aditama, Bandung.

Ardana, Mujiati dan Utama, (2012). Manajemen Sumber Daya Manusia, Graha Ilmu, Yogyakarta.

Arikunto, Suharsimi, (2006). Prosedur Penelitian suatu pendekatan Praktik, Jakarta : PT Rineka Cipta.

Asri,(1986). Manajemen Perusahaan dan Pendekatan Operasional, BPFEUGM, Yogyakarta.

Bastian, Budaya Organisasi dalam Lingkungan Kerja, Bandung PT Riengka Cipta 2007

Freddy Rangkuti. (2015). "Analisis SWOT membedah kasus bisnis". Jakarta Erlangga

George R. Terry, (2010). Prinsip prinsip Manajemen, Bumi aksara, Jakarta. 
Handoko, (2003). Manajemen, BPFEUGM, Yogyakarta.

Hariandja, (2002). Manajemen Sumber Daya Manusia, Grasindo, Jakarta.

Hasibuan, (2003). Manajemen Sumber Daya Manusia, PT Bumi Aksara, Jakarta.

Ishak Arep dan Tanjung, (2002). Manajemen Sumber Daya Manusia, Trisakti, Jakarta.

Mulyadi, (2007).Membangun kinerja sumber daya manusia yang efektif, Bumi Aksara

Phiti sithi amnuai. (1989). "how to build a coporation culture" Asian Manager

Porter, (1985). organizational citizenship behavior and culture, Jakarta, Tempo

Philip Kotler, (2008). Manajemen Pemasaran, jakarta, gramedia

Robbins dan Coulter, (2007). Manajemen Jilid Satu, Rineka Cipta, Jakarta

Stoner, freeman dan Gilbert, organizational culture, jakarta, gramedia, 2001

Simamora, Henry, 2006, Manajemen Sumber Daya Manusia, Yogyakarta : STIE YPKN.

Sutrisno, Edy, (2010). Budaya Organisasi, Jakarta : Kencana Prenada Media Group.

Tohardi, Ahmad. (2002). Pemahaman Praktis Manajemen Sumber Daya Manusia, Bandung: Mandar Maju.

Umar Nimran, budaya organisasi dalam kerja, jakarta, gramedia,
Veithzal Rivai.2008, Manajemen Sumber Daya Manusia Untuk Perusahaan Dari Teori Ke Praktik, PT. Raja Grafindo Persada, Jakarta

Wirawan, (2012), Profesi dan Standar Evaluasi, Yayasan \& UHAMKA PRESS, Jakarta.

Dewita Heriyanti Analisis Pengaruh Budaya Organisasi, Kepuasan Kerja, Dan Gaya Kepemimpinan Terhadap Kinerja Karyawan Dengan Komitmen Organisasi Nasional Sebagai Variabel Intervening PT. (persero) PLN APJ Semarang.

Triyogo Agung Wibowo (2008) dalam tesisnya "Analisis Pengaruh Budaya Organisasi Dan Kepuasan Kerja Terhadap Motivasi Kerja Dan Kinerja Karyawan BRI Cabang Semarang.

Nugi Keran (2012) dalam tesisnya "Pengaruh Motivasi Kerja, Kompetensi, Dan Kompensasi Terhadap Kinerja Karyawan di Yayasan Bintang Timur Tangerang.

I Made Yusa Dharmawan (2011) dalam tesisnya “ Pengaruh Kompensasi dan Lingkungan Kerja Non Fisik Terhadap Disiplin Kerja Dan Terhadap Kinerja Karyawan di Hotel Nikki Denpasar Bali.

Diah Indiana Dewi (2012) dalam tesisnya " Pengaruh Kompensasi dan Penilaian Kinerja Terhadap Employee Engagement di PT. 
Jasa Asuransi Indonesia

(Persero) Jakarta.

Adrid Indaryanto (2008) dalam tesisnya "Pengaruh Pelatihan,

Budaya Organisasi Terhadap

Kinerja Apprencites. 